Journal of Teacher Education for Sustainability, vol. 19, no. 1, pp. 5-21, 2017

\title{
Education for Sustainable Consumption through Mindfulness Training: Development of a Consumption-Specific Intervention
}

\author{
Laura Stanszus ${ }^{1}$, Daniel Fischer ${ }^{2}$, Tina Böhme ${ }^{1}$, Pascal Frank ${ }^{2}$, \\ Jacomo Fritzsche ${ }^{3}$, Sonja Geiger ${ }^{1}$, Julia Harfensteller ${ }^{4}$, \\ Paul Grossman ${ }^{5}$, and Ulf Schrader ${ }^{1}$ \\ ${ }^{1}$ Technische Universität Berlin, Germany \\ ${ }^{2}$ Leuphana University of Lüneburg, Germany \\ ${ }^{3}$ Institute for Mindfulness and Sustainability (IfAN) Berlin, Germany \\ ${ }^{4}$ Institute for Mindfulness and Health (SAGE), Berlin, Germany \\ ${ }^{5}$ European Centre for Mindfulness (EzfA), Germany
}

\begin{abstract}
Several widespread approaches to Education for Sustainable Consumption (ESC) have emerged from the tradition of consumer information. A major shortcoming of such cognitive-focused approaches is their limited capacity to facilitate reflection on the affective processes underpinning people's engagement with consumption. More holistic pedagogies are thus needed to increase the effectiveness of ESC. The concept of mindfulness has recently received growing attention in research on sustainable consumption, given its potential to address both cognitive and affective processes and to stimulate reflection on the drivers of often routinized consumption practices. Despite this recent interest, mindfulness has to date not been systematically connected to ESC. This paper provides a reflexive case study of the development of mindfulness-based intervention (MBI) specifically tailored to ESC ("BiNKA-training"). It elaborates the conceptual connections between mindfulness and ESC, offers insights into the process of adapting MBI to ESC and concludes with lessons learnt and an outlook on future work seeking to tap the potential of MBIs to form more holistic approaches to sustainability education. Keywords: education for sustainable consumption, mindfulness-based stress reduction, curriculum development, mindfulness, ethics, sustainable consumption, values, intervention design.
\end{abstract}

\section{Aim of the Paper}

This paper provides a reflexive case study of the development of a mindfulness training programme specifically tailored to the context of Education for Sustainable Consumption (ESC), the so-called BiNKA-training. The training is a core element of 
the research and development project BiNKA (German acronym for "Education for Sustainable Consumption through Mindfulness Training") set out to empirically investigate the relationship between mindfulness and sustainable consumption with an intervention study.

The first section of the paper provides some background by discussing the relevance of mindfulness for ESC. The second section describes the research in the foundational phase. A critical step in this phase of the development process was the selection of adequate components from the two fields of mindfulness-based interventions (MBIs) and ESC that were then to be assembled to create a consumption-specific MBI. The third section expands on how the findings of the previous phases were integrated and used to build, test and revise the prototype of the BiNKA-training. The final design and curriculum of the training is presented that has resulted from this process. The paper concludes by offering some critical reflections of the development process, lessons learnt in this transdisciplinary endeavour and ways forward for future work in this field.

\section{Mindfulness and Education for Sustainable Consumption: Making the Connection}

The nexus of education, consumption and sustainable development has been at the top of the agenda since the very inception of the political process towards sustainable development at the Rio Conference in 1992. Today, 25 years later, both education for sustainable development (ESD) and sustainable consumption (SC) are prominently addressed as distinct Sustainable Development Goals (numbers 4 and 12) in the United Nations' post-2015 agenda (United Nations, 2015). Education for Sustainable Consumption has emerged as a field of scholarship, policy and educational practice that aims at connecting the discourses around consumer education, ESD and sustainable consumption (Adomßent et al., 2014). ESC extends the scope of traditional consumer education approaches that were guided by the ideal of the informed consumer and consequently emphasised awareness raising and the transmission of information and knowledge to foster individual behavioural change (McGregor, 2005). With ESC comes a greater appreciation of and engagement with notions such as civic agency and citizenship, ethical considerations (e.g., good life, responsibility) and the overall aim to strengthen the capacity of consumers to contribute to a broader societal transformation towards sustainable development. This reorientation went alongside the development of more comprehensive learning outcomes that had been conceptualized as key competencies for sustainable consumption (Fischer \& Barth, 2014; Rieckmann, Mindt, \& Gardiner, 2017). Key competencies as learning objectives in ESC seek to (1) nurture cognitive, motivational and volitional dispositions, (2) are guided by the idea of critical, selfdetermined and self-reflexive individuals and (3) promote the capacity of learners to actively and responsibly contribute to advancing overall societal progress towards sustainability. To this end, it facilitates the deliberative processes underpinning social change, instead of simply pursuing behavioural change as a primary educational objective (for a more comprehensive discussion see Fischer \& Barth, 2014). A major task for research in ESC is thus to advance learning settings that effectively address both cognitive and affective learning outcomes and promote a reflexive engagement with sustainable consumption challenges. Given the predominance of cognitive approaches in traditional consumer education, there is a strong need to advance a deeper engagement with affective processes in ESC. 
Mindfulness has the potential to support this endeavour and strengthen ESC in multiple ways. It is defined here as the unbiased awareness that emerges through intentionally and continuously paying attention to subjective momentary experience with an open, accepting, benevolent, and compassionate attitude (Boehme et al., 2016). The concept of mindfulness has been increasingly researched in recent years, originally mainly in the clinical context, expanding into behavioural research (for more information see Bowen et al., 2006; Grossman, Niemann, Schmidt, \& Walach, 2004) and beyond science into multiple societal areas, e.g., education (see, e.g., Mindfulness All-Party Parliamentary Group, 2015).

In general, mindfulness is considered to bear the potential to bring together cognition and affection, thus extending and complementing dominating concepts of ESC. It is seen to encompass the reflection of individual values and actions in each given moment and therewith to potentially strengthen people's ability to deliberatively focus their mind in a way that they become more sensitive for their own values, emotions and ensuing actions. This ability would promote the alignment of intentions with actual behaviour and consequently the adaption of actions towards more sustainable consumption patterns. The ongoing, mainly conceptual discussion of how mindfulness can promote positive changes in consumption behaviour and support (E)SC will be summarised in the following four main potential mechanisms of change (for a more comprehensive review of the current literature see Fischer et al., 2017):

(1) Disruption of routines or switching off the autopilot (Grossman et al., 2004) by enhancing introspective capacities and thus providing the grounds for changing previously unconscious routines is a broadly recognised potential effect of mindfulness practice. For ESC this could mean that unconscious, non-sustainable consumption choices could be elucidated and diminished (Rosenberg, 2004; Bahl et al., 2016).

(2) Secondly, mindfulness practice is deemed to support an enhanced awareness of immediate daily experiences. In the current research, it has been shown to reduce self-perceived inattention to ones' own behavioural patterns which is associated with the attitude-behaviour-gap (Chatzisarantis \& Hagger, 2007). That way, it is associated with a greater capacity to make more congruent choices that may potentially narrow the attitude-behaviour-gap and support more sustainable consumption patterns (Ericson, Kjønstad, \& Barstad, 2014; Rosenberg, 2004).

(3) Mindfulness practice may thirdly be conducive to the clarification of values and supporting the role of non-material values in people's lives (Ericson et al., 2014). According to Buddhist psychology, mindfulness practice has the aim of counteracting unwholesome qualities (greed, delusion, aversion - which are frequently referenced in sustainability literature, too) by cultivating openness, generosity, kindness and mental clarity (Grossman, 2015). The fostering of such benevolent attitudes is also thought to increase individual well-being, which in turn is associated with an increase in intrinsic and socially oriented values and behaviour and a decrease in materialistic, hedonistic values (Kasser et al., 2014; Burroughs \& Rindfleisch, 2002; Richins \& Dawson, 1992).

(4) Lastly, the fourth mechanism refers to recent findings according to which pro-social behaviours are explicitly increased through meditation practices 
(Lim, Condon, \& DeSteno, 2015; Leiberg et al., 2011). This process is seen to be initiated through the development of compassion (especially in otheroriented techniques such as loving-kindness/metta meditation) (Condon et al., 2013). Pro-social behaviour is consecutively positively linked to proenvironmental intentions and behaviour (Pfattcheicher et al., 2016; de Groot and Steg, 2008; Steg et al., 2014, in Fischer et al., 2017).

Despite the apparent conceptual connections and the increased interest of researchers, the potential of mindfulness for (E)SC so far remains a scarcely researched area (Rosenberg, 2004), even less so when it comes to intervention studies (Fischer et al., 2017).

\section{Laying the Foundations}

In the initial phase of development, both existing MBIs and potentially suitable ESC-formats were screened and reviewed to identify solid foundations to build the BiNKA-training on.

\section{Mindfulness-Based Interventions}

In recent years, numerous mindfulness-training formats have been conceptualised. One of the first tasks in developing the training was to analyse existing formats with regard to their suitability to serve the objectives of the proposed intervention. This analysis was predicated on seven criteria elaborated by the research team (see Harfensteller, 2016, for a more detailed discussion of the process). The MBI to be chosen should

(1) be empirically tested and validated;

(2) be multiple-week-long with daily individual practice as well as one longer session to account for the need of a regular meditation practice to induce physiological changes (Carmody \& Baer, 2008);

(3) have a clear focus on mindfulness meditation instead of multiple/other meditation techniques, e.g., transcendental meditation;

(4) contain mostly exercises and practices that include experience-based knowledge and are highly applicable to and integrable into participants day-to-day-life (daily-life focus);

(5) provide the possibility for thematic combination of meditation practice with the topic of (sustainable) consumption (especially food and clothing) to allow for the integration of ESC elements (consumption focus);

(6) incorporate both cognitive and affective training units for key competencies that are deemed relevant to an experienced meditation teacher as well as current research on the topic of ESC (Carmody \& Baer, 2008; Ericson et al., 2014; Fischer \& Barth, 2014) (BiNKA-training focus);

(7) be specific to the project target groups (secondary school students, university students, employees) or be easily adaptable to them. 
Table 1

\begin{tabular}{|c|c|c|c|}
\hline MBI & MBSR & MBCT & MSC \\
\hline Name & $\begin{array}{l}\text { Mindfulness-Based } \\
\text { Stress Reduction }\end{array}$ & $\begin{array}{l}\text { Mindfulness-Based } \\
\text { Cognitive Therapy }\end{array}$ & $\begin{array}{l}\text { Mindful } \\
\text { Self-Compassion }\end{array}$ \\
\hline Author/year & $\begin{array}{l}\text { John Kabat-Zinn/ } \\
1979\end{array}$ & $\begin{array}{l}\text { Zindel Segal \& Mark } \\
\text { Williams/2008 }\end{array}$ & $\begin{array}{l}\text { Kristin Neff \& Christ- } \\
\text { opher Germer/2015 }\end{array}$ \\
\hline Source & umassmed.edu/cfm & oxfordmindfulness.org & $\begin{array}{l}\text { centerformsc.org/ } \\
\text { meditations }\end{array}$ \\
\hline Objective & $\begin{array}{l}\text { Secular stress-reduction } \\
\text { programme based on the } \\
\text { four pillars of traditional } \\
\text { mindfulness practice }\end{array}$ & $\begin{array}{l}\text { Programme for people } \\
\text { with psychological ill- } \\
\text { ness, mainly depression, } \\
\text { based on MBSR }\end{array}$ & $\begin{array}{l}\text { Programme to develop } \\
\text { self-compassion and } \\
\text { emotional resources for } \\
\text { healthy people, loosely } \\
\text { based on MBSR }\end{array}$ \\
\hline $\begin{array}{l}\text { Time } \\
\text { requirements }\end{array}$ & $\begin{array}{l}8 \text { sessions à } 2.5-3 \text { hrs, } \\
1 \text { session } 4 \text { hrs, } 45 \text { min. } \\
\text { individual practice, } 6 \\
\text { times a week }\end{array}$ & $\begin{array}{l}8 \text { sessions à } 2.5 \text { hrs, } \\
1 \text { session } 4 \text { hrs, } 45 \text { min. } \\
\text { individual practice, } 6 \\
\text { times a week }\end{array}$ & $\begin{array}{l}8 \text { sessions à } 2.5 \text { hrs, } \\
1 \text { session } 4 \text { hrs, } 30 \text { min. } \\
\text { individual practice, } 7 \\
\text { times a week }\end{array}$ \\
\hline $\begin{array}{l}\text { Consumption } \\
\text { focus }\end{array}$ & $\begin{array}{l}\text { Mindful eating exercise } \\
\text { on the Day of Mindful- } \\
\text { ness }\end{array}$ & Not observed & Not observed \\
\hline Daily-life focus & $\begin{array}{l}\text { Diary of pleasant and } \\
\text { unpleasant daily situ- } \\
\text { ations }\end{array}$ & $\begin{array}{l}\text { Exercise "Walking the } \\
\text { street" mindfully, } \\
\text { group reflection }\end{array}$ & $\begin{array}{l}\text { Exercise "Promise to } \\
\text { myself", reflect on prior- } \\
\text { ities in everyday life and } \\
\text { learn to focus on them }\end{array}$ \\
\hline $\begin{array}{l}\text { BiNKA- } \\
\text { training focus }\end{array}$ & $\begin{array}{l}\text { (1) Self-acceptance, trust } \\
\text { and gratefulness are } \\
\text { repeatedly addressed } \\
\text { (2) Exercise to eat a meal } \\
\text { mindfully and observe } \\
\text { what you really need }\end{array}$ & Not observed & $\begin{array}{l}\text { (1) Dealing with (dif- } \\
\text { ficult) feelings is at the } \\
\text { core of the training } \\
\text { (2) Raising awareness of } \\
\text { one's own needs }\end{array}$ \\
\hline
\end{tabular}

Mindfulness-Based Stress Reduction (MBSR) was chosen as the format most suitable according to the selection criteria. The programme was developed in 1979 at the Centre for Medicine, Health Care and Society of the Massachusetts University Medical School by Jon Kabat-Zinn, originally for the treatment of chronic pain patients. It runs for 810 weeks, with typically a single 2.5 -3-hour group session a week, one additional allday session and individual 45-min daily meditation practice, mindful yoga exercises, and informal mindfulness in daily live (Kabat-Zinn, 1991).

The format is most widely used and validated in mindfulness research to date and its effects have been repeatedly confirmed in multiple studies with healthy and clinical populations (Grossmann, 2004; Creswell, 2017). In light of this, the MBSR format is considered a solid benchmark for effective mindfulness trainings. Furthermore, despite its secular focus, it is closely aligned with the traditional Buddhist understanding of mindfulness and comprises all conventional mindfulness practices (Kabat-Zinn, 2011). Another reason for prioritising MBSR over the other available formats is the programme suitability for more than one target group as well as the possibility for adapting it to different thematic contexts. As shown in the development of Mindfulness-Based Cognitive- 
Therapy (MBCT, Teasdale et al., 2000), it is possible to accommodate didactic and content in the MBSR programme structure without compromising the major aim of developing mindfulness competency.

\section{Education for Sustainable Consumption: Formats}

The development of the BiNKA-training was further implemented by a review of different ESC formats (Fischer, 2016). Rather than achieving comprehensiveness, the review sought to identify different educational formats that could be of use for adapting general mindfulness training to the specific thematic and institutional contexts of the BiNKA-Training. In the review, educational formats were defined as distinct practical approaches used in pedagogical work to foster learning processes in the field of sustainable consumption. Such practical approaches may comprise assignments, exercises and other learning activities that include specific requests to learners. Educational formats were considered relevant when they were compatible with:

(1) the distinct time limitations imposed by the format of an 8-week mindfulness training;

(2) the thematic scope of the mindfulness training that was focused on reflection of needs and personal development as well as on consumption in the areas of food and clothing;

(3) the distinct populations targeted in the BiNKA-training (secondary school students, university students, employees); and

(4) the competence orientation of the mindfulness training that focused on awareness, reflection and sensations.

Educational formats were collected from the two most prominent strands in ESC: consumer education and ESD. Data was collected from two popular German reference databases for learning materials from both strands (www.bne-portal.de and www.materialkompass.de). The selected formats were then clustered according to two aspects: their thematic focus (happiness and needs, food and clothing, consumption and advertising and personal development) and the competencies primarily addressed by the formats (awareness of problems and one's individual impact on them, personal values, norms and needs and aspects of external and self-determination). The clusters were not meant to be distinct, but rather indicated emphasis on the materials reviewed. As a result of the review, several educational formats from the field of ESC with different thematic and competence-related foci were identified (see examples in Table 2).

Table 2

Examples of Potentially Relevant ESC Educational Formats for the BiNKA Curriculum

\begin{tabular}{lllll}
\hline $\begin{array}{c}\text { Educational } \\
\text { format }\end{array}$ & Needs analysis & \multicolumn{1}{c}{ Food diary } & $\begin{array}{c}\text { Brands make } \\
\text { friends }\end{array}$ & \multicolumn{1}{c}{ I am OK } \\
\hline Type & Group exercise & Written task & Creative design & Self-reflection \\
\hline Objective & $\begin{array}{l}\text { To reflect human } \\
\text { needs and strat- } \\
\text { egies of need } \\
\text { satisfaction }\end{array}$ & $\begin{array}{l}\text { To document } \\
\text { nutrition behav- } \\
\text { iour and reflect } \\
\text { on it }\end{array}$ & $\begin{array}{l}\text { To raise aware- } \\
\text { ness of how } \\
\text { branding has been } \\
\text { internalised }\end{array}$ & $\begin{array}{l}\text { To gain confidence } \\
\text { in one's own } \\
\text { capabilities }\end{array}$ \\
\hline
\end{tabular}


Sequel to Table 2.

\begin{tabular}{|c|c|c|c|c|}
\hline Description & $\begin{array}{l}\text { Learners work on } \\
\text { guiding questions } \\
\text { to identify strat- } \\
\text { egies used to meet } \\
\text { needs }\end{array}$ & $\begin{array}{l}\text { Learners observe } \\
\text { and record their } \\
\text { eating practices for } \\
\text { a defined time } \\
\text { period }\end{array}$ & $\begin{array}{l}\text { Learners dress a } \\
\text { person on paper } \\
\text { with branded } \\
\text { fashion items and } \\
\text { discuss it }\end{array}$ & $\begin{array}{l}\text { Learners describe } \\
\text { positive changes } \\
\text { accomplished from } \\
\text { a future retro- } \\
\text { spective }\end{array}$ \\
\hline $\begin{array}{l}\text { Time } \\
\text { requirements }\end{array}$ & 90 minutes & 60 minutes & 25 minutes & 30 minutes \\
\hline $\begin{array}{l}\text { Competence } \\
\text { focus }\end{array}$ & $\begin{array}{l}\text { Personal values, } \\
\text { norms and needs }\end{array}$ & $\begin{array}{l}\text { Awareness of } \\
\text { problems and one's } \\
\text { individual impact } \\
\text { on them }\end{array}$ & $\begin{array}{l}\text { Aspects of external } \\
\text { and self-determ- } \\
\text { ination }\end{array}$ & $\begin{array}{l}\text { Personal values, } \\
\text { norms and needs }\end{array}$ \\
\hline $\begin{array}{l}\text { Thematic } \\
\text { focus }\end{array}$ & $\begin{array}{l}\text { Happiness and } \\
\text { needs }\end{array}$ & Food and clothing & $\begin{array}{l}\text { Consumption and } \\
\text { advertising }\end{array}$ & $\begin{array}{l}\text { Personal develop- } \\
\text { ment }\end{array}$ \\
\hline
\end{tabular}

\section{Developing the BiNKA-Training}

As the development of the training has undergone through numerous stages that may prove relevant for further development of similar interventions, the following part describes the decisions that have formed the design of the final curriculum in some greater detail. After that, the final curriculum is presented.

\section{Development: Finding the Balance}

A major challenge in the process of developing the training was to find the balance between mindfulness elements (both cognitive and affective) and ESC elements (that are mostly cognitive-based) compromising neither the key practice of mindfulness, nor the educational requirements of ESC (see Figure 1).

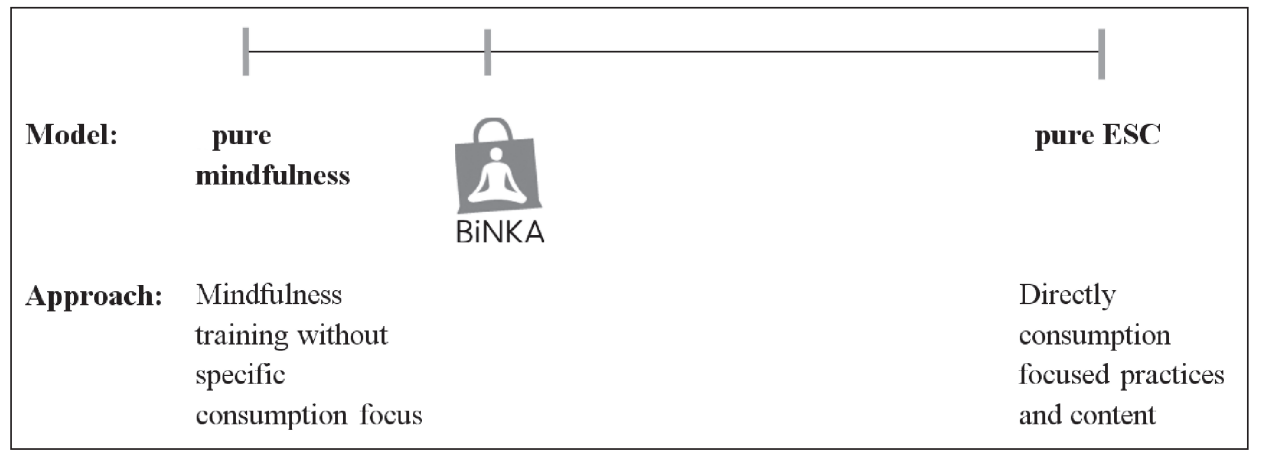

Figure 1. BiNKA-training on the spectrum between mindfulness and ESC

The initial consideration of potentially valuable ESC elements for the BiNKA-training, as well as the most suitable foundation of a mindfulness programme was subject to a thorough discourse in the transdisciplinary project team. Psychologists, ESC and sustainability experts as well as mindfulness experts from both theory and practice discussed the preliminary results of the reviews of the prior development phase and mutually decided on keystones for the subsequent development steps. 
A persistent controversy was surrounding the question of blending and balancing ESC and mindfulness elements. On one side of the controversy, there was an assumption that adapting the training too little and remaining too close to "pure mindfulness" would hardly impact consumption-related attitudes and behaviours. On the other hand, it was argued that adapting the original MBSR format too much toward "pure ESC" training would diminish the benefits associated with a certain intensity of mindfulness training and reliance on a regular and consistent practice. What was agreed upon was that the explicit intention of the training was to make people consume in a more sustainable way, according to their own consumption-related values. The mean for propelling that change was primarily the cultivation of introspective capacities, potentially leading to an increased awareness of one's needs and (partially unconscious) consumption patterns. A risk was seen in the provision of too overtly consumption-related information, as this might potentially confound these intrinsic values with extrinsic normative ideas. Moreover, there would have been a risk of participants perceiving the training as intrusive, or even manipulative, in the sense that they felt pushed to consume in a certain way when presented with a lot of fact-based ESC input. Consequently, it was decided to limit the conveyance of such input within the training to a minimum. Another aspect in support of this decision referred to the evaluation of possible effects of the training. A high dose of ESC fact-based input would have made it impossible to attribute measured changes in consumption behaviour to mindfulness practice. However, as the main objective underpinning the research project was to elucidate the potential of mindfulness to promote the acquisition of key competencies and foster sustainable consumption, it was decided to orientate the training closer towards classical mindfulness training than an ESC course.

\section{Initial Training Blueprint}

For the construction of the BiNKA-training, several adaptations of the traditional MBSR format were needed. Firstly, in order to meet the practical constraints of the target groups (especially the employees at their companies and the secondary school students at school), the sessions were shortened from 150 to 90 minutes as well as the daily practice from 45 to 20 minutes for adults and 15 minutes for secondary school students, respectively. Secondly, the selected ESC as well as consumption-specific mindfulness elements had to be included in the training. Thus, some MBSR-specific content had to be eliminated in order to make space for ESC elements in an already diminished time frame, which led to a fundamental restructuring of the entire training. On the grounds of the initial analysis and the ensuing team debates, the MBSR teacher team developed a first detailed blueprint of the training, which was presented to the entire research team and, after minor adjustments, piloted in two settings (with university students and employees). After the completion of the pilot trainings, interviews were conducted with participants and the course teachers and the results were fed back and discussed with the team.

\section{Revision and Secession School Training}

At this point of revision, some elements were considered unsuitable and thus removed from the curriculum. An example for this is an exercise that exposed participants to photographs of factories with poults (consumption area of food) or female sewers working 
under insupportable conditions (consumption area of clothing), and asked them to observe their thoughts, feelings and body sensations. Other elements such as the task to go shopping in a mindful way turned out to be suitable for the context of the training and were kept in the curriculum and given more time if needed and possible. Thus, based on those findings and changes, the structure and timing of each session was refined again.

While initially the training with secondary school students (grade 10, aged 15-16) and adults was identical, it became clear during 2 test runs that the school training required more fundamental and specific changes of the initial blueprint. This was due to the special preconditions of the target group (adolescents) and the setting (implementing the training into the school context). For example, it showed effective to include a higher frequency of switching between sitting and standing/walking, as well as to allocate time during sessions to reflect on certain questions in written form as a preparation and basis for group discussions. The adaptation process was inspired by a literature review on mindfulness programmes and formats especially for children and adolescents (e.g., Broderick \& Frank, 2014; Kaltwasser, 2008; Meiklejohn et al., 2012; Rechtschaffen, 2016).

\section{Result: The BiNKA Curriculum}

The final BiNKA-training for all target groups comprises eight weekly sessions of 90 minutes and one longer session ("Day of Mindfulness") of four hours. The training sessions are built on one another and intertwined in form and content. In the first half of the training, the sessions are more mindfulness-focused, whereas in the second half, they are more consumption-specific. The topics of the BiNKA-session are the following:

1. Introduction - What is Mindfulness?

2. Obstacles and Challenges in Meditation

3. (Dis-)Satisfaction and Other Similarities

4. Emotional Intelligence - Be Mindful with what You Feel

5. Desires and Needs - Open Up towards Life

6. Compassion - Kindness towards Myself and Others

+1 Day of Mindfulness - Discover the Silence together

7. Mindful Consumption - To Have and to Be

8. A Mindful World - Inside Out

The topic of each session is addressed in "insight talks" between a teacher and participants, reflexive dyads/triads or group discussions as well as in the guided meditation practice (see Figure 2 for a more detailed overview of the different elements used in a prototypical session). Each session includes formal and informal mindfulness exercises. The formal mindfulness practice refers to a practice with a clearly defined procedure and time frame and comprises different types of mindfulness meditation such as body scan, sitting and walking meditation with focus on the breath, and loving kindness/ metta meditation. The informal mindfulness practice aims at transferring mindfulness into everyday life activities such as eating, shopping, showering, or walking. The "Day of Mindfulness" involves an intensive formal practice of mindfulness meditation as well as mindful potluck meal in silence. In addition to the weekly training sessions, the participants are encouraged to practice formal meditation autonomously on a daily basis (20 minutes for employees and university students and 15 minutes for secondary school students) and keep a practice diary on their experiences and reflections. In order 
to support the participants in these autonomous practices, audio recordings of guided meditations are provided (see mindfulness-and-consumption.de for sample downloads). Moreover, the participants get a specific task to practice mindfulness informally at home (e.g., "mindful shopping”).

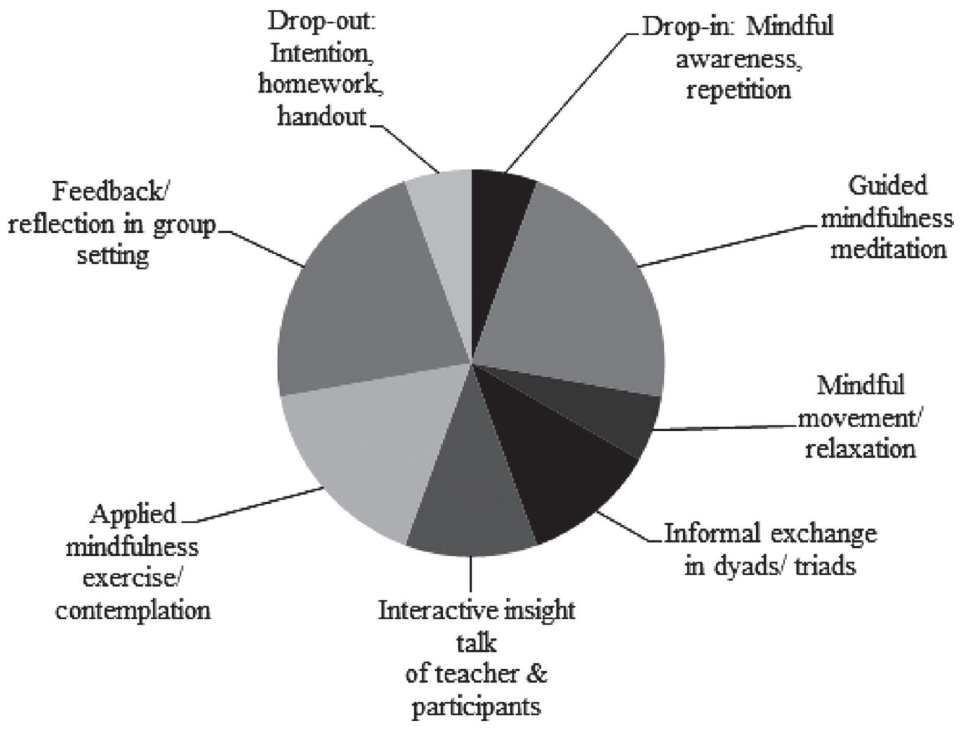

Figure 2. Elements of a prototypical BiNKA-session (proportions vary depending on session focus and group dynamics)

To give a more thorough impression of BiNKA-specific content, three concrete examples from different stages of the training are illustrated hereafter. The chosen examples are exemplary for (1) newly constructed, consumption-specific mindfulness exercises, (2) the fusion of an ESC format with mindfulness practice, and (3) the adaptation (e.g., deepening) of certain MBSR content to promote the ethical stance inherent in mindfulness considered relevant for sustainable consumption. Session 7 "Mindful Consumption - To Have and to Be" represents the most consumption-focused session of the BiNKA-training and is described in detail in appendix I.

(1) The homework "Mindfulness in Everyday Life: Mindful Shopping” aims at facilitating the introspection and reflection of subjective (consumption-specific) behavioural patterns and invites the participants to go shopping with a conscious activation of all of their senses. Participants are asked to slow down their usual routine so that they are able to observe their body sensations, their thoughts, and feelings more closely in any given consumption situation they select (e.g., shopping for groceries or clothes). The participants are then asked to reflect on their observations and to write them down in their practice diaries (week 1).

(2) The exercise "Interdependence: A Pair of Jeans Travels around the World" combines ESC and mindfulness and seeks to increase the participants' awareness of the social and global dimensions of their personal consumption practices as well as their capacity to reflect on these dimensions. The participants are guided through the different stages of the production of blue jeans in a visual 
journey and constantly encouraged to be in contact with their sensory experience (e.g., the feeling of their pants on their legs) and other inner reactions (e.g., thoughts, emotions) (week 7).

(3) The practice of loving kindness/metta meditation has been more deeply embedded in the BiNKA-training than it is found in standard MBSR interventions. The reason for this is that the qualities addressed by these types of practices (namely benevolence and compassion) are closely connected to the reflection and transformation of one's behaviour and were thus deemed as crucial by the project team (see Section 2). Metta meditation is introduced in two steps: first, the practice of embodied kindness and compassion towards oneself; second, expanding that practice by including others (people, living beings, nature). Apart from the practice and reflection in the training session, the participants are encouraged to read a text written by the trainer on "Mindfulness in Action The Embodiment of Compassion" in the course handout as well as to practice the embodiment of compassion in their everyday lives (week 5 to 8 ).

\section{Critical Reflection and Lessons Learnt}

As described before, the BiNKA-training is consumption-specific mindfulness intervention that was developed to contribute to the advancement of ESC by strengthening affective learning and exploring the potentials of mindfulness to make changes towards more sustainable consumption practices. During the process of developing the training, certain aspects of the initial strategies were proved to be useful and were extended, while others turned out to be less helpful with regard to the overall purpose of the project. Two major lessons learnt are particularly relevant for the application of adapted MBIs within the framework of ESC and will be critically reflected hereafter: (1) emphasis should be laid on practices that stimulate participants' engagement with their inner affective processes and help to elucidate these processes and make them accessible for reflection (e.g., through self-discovery and openly turning to individual ethical values, needs and behavioural patterns) rather than on external cognitive input; (2) for mindfulness practices to unfold their full and long-lasting potential for ESC, continuous practice and re-examination of consumption-related processes and experiences are required rather than one-shot intervention.

\section{Rather Affective and Implicit than Cognitive and Explicit Learning Strategies}

\section{Focusing on Introspection and Self-Discovery}

Steady voluntary personal engagement and comprehension are fundamental for any kind of affective learning (Nelson \& Creagh, 2013; Bandura \& Schunk, 1981). This holds especially true for introspection processes as they are very individual tasks, which neither can be guided nor observed beyond a certain threshold by any external entity/person. Furthermore, specific and ongoing training is required to acquire awareness of those - mostly unconscious - inner occurrences that inherently impact everyday behaviour and underlying bodily functions (Petitmengin, 2006). As Petitmengin states, "Our most immediate and most intimate experience that which we live here and now is also that most foreign to us and the most difficult to access" (Petitmengin, 2006, p. 230). The need to focus on supporting the emergence of introspection/self-reflection and affec- 
tive competencies to explore - and thus become able to change - individual (consumptionrelated) values, attitudes and actions proved to be an essential insight to take from the process of developing the training, far more than was expected beforehand.

\section{Promoting Implicit Ethical Values of Mindfulness}

In contrast to affective learning and introspection, cognitive focused learning is more concerned with the acquisition of external information and conscious thought processes (Bandura \& Schunk, 1981). Ethical or moral values conveyed in that way may trigger resistance or superficial acceptance that does not change individual value systems. The practice of mindfulness, on the other hand, envisages ethical development based on intuitive and affective understanding of what is right and wrong (Monteiro, Musten, \& Compson, 2014). In traditional mindfulness and Buddhist teachings, the practice of meditation and awareness of our body/mind experiences bear the intention to transform the aforementioned unwholesome emotions and actions (namely greed, anger and delusion) into wholesome or "right" emotions and ethical actions (namely generosity, compassion and wisdom) (Grossman, 2015) in order to help alleviate suffering in oneself and the world. It is notable that, despite the minor stance, ethical education took so far in contemporary mindfulness research (Monteiro, 2016). Kabat-Zinn in the creation of MBSR has stressed the importance of MBIs to be grounded in a universal "dharma" understanding that is congruent with Buddhist dharma, but not constrained by traditions (Kabat-Zinn, 2011). The aim of the training was to support participants' capacity to reflect on their needs and increase their awareness of the ethical values they hold. Thus, it emerged as increasingly important in the course of developing and focusing of the training to consider the ethical dimension of mindfulness more strongly throughout the course of sessions.

\section{Long-Lasting Change through Long-Term Practice instead of Short-Lasting Change through Short-Sighted Interventions}

\section{Behaviour Change Takes Time}

One of the key characteristics of the BiNKA-training is its understanding of mindfulness that is rooted in the genuine ethical background of MBSR and mindfulness in Buddhism. According to this positioning, the aim was to stimulate reflection of intrinsic moral values and perceived inconsistencies in terms of attitude-behaviour-gaps, rather than to induce short-term and likely superficial changes on the behavioural level. Radical shifts in consumption patterns based on self-reflected ethical values, however, may take time to realise - presumably more time than an 8-week-training course can provide. This does not mean that consumption-specific mindfulness intervention is ineffective, but is important to consider when evaluating behavioural effects resulting from participation in the BiNKA-training.

\section{Mindfulness Practice and SC Knowledge: A Hermeneutic Circle}

Consideration of personal needs, (sustainable) consumption patterns and ethical values will per se depend on the individual knowledge base of sustainable consumption of the individual. To put it the other way round: practice and experience in mindfulness are required to be able to develop the ability for advanced introspection and, thus, to recognise one's own unconscious behavioural patterns in the area of (sustainable) con- 
sumption. As stressed, such awareness is pivotal for aligning one's own behavioural patterns more closely to inherently held values. Little or no prior knowledge of sustainable consumption provides a less nuanced ground for reflection than a more comprehensive understanding of the challenges inherent in consumption practices. Even though, as clearly stated above, there are good reasons to keep the conveyance of extrinsic consumption related values and cognitive ESC knowledge to a minimum; reliance on "plain" mindfulness practice without a certain background for the introspection would not support ESC either. Thus, rather than to conceptualise (cognitive) knowledge of (sustainable) consumption (as a contribution of ESC) and the ability to reflect on affective processes in one's own consumption behaviour (as a contribution of mindfulness) as two separate entities, both are more appropriately understood as interacting and potentially reinforcing each other as they evolve and mature. Therefore, traditional one-time intervention may have only limited effects. Against this background and based on the experiences made in the development and implementation of the training, the project team concluded that it might be fruitful to integrate mindfulness and ESC over a longer period of time (while possibly less time-intensive and with a higher focus on individual practice) in a hermeneutic circle or spiral to further increase the potency of the intervention. This may also involve a more explicit ESC-oriented course prior or in parallel to the BiNKA-training instead of trying to minimise information about the inclusion of consumption-related content in advance of the training.

\section{Conclusion}

The starting point of this paper has been that there is a need to overcome the predominance of cognitive approaches in ESC and to stimulate a more holistic engagement with affective processes in learners. The critical case study presented on the development and implementation of consumption specific mindfulness training in educational settings has provided some insights that may promote future work in the field. The task itself required a team of both researchers from different fields and practitioners experienced in guiding learners in mindfulness. The assembly of the team ensured that the development of the curriculum was implemented by a rich and diverse body of different knowledge backgrounds and that quality criteria from different fields were met. The process of codesigning the training also revealed that values acted as a key concept in all related fields. Hence, future research on consumption-specific mindfulness trainings in educational settings may seek to further elaborate on the role of values and ethics. A possible next step can be to incorporate ethical education more explicitly as from a "right" mindfulness perspective, cultivating the "Noble Person" that transcends self-interest and lives for the well-being of others (Monteiro, 2016; Grossman, 2015). This may also benefit from a deeper understanding of mindfulness (Bodhi, 2011) and help respond to the challenge that, if not adequately met, may limit the potential of mindfulness for ESC. The challenge is the extension of the scope of mindfulness to a broader issue of social change and the reform of structures of systems of consumption and production. If mindfulness remains confined to the immediate inner world and to private consumption practices, it may effectively prevent the transformation of political and economic structures sustaining unsustainable consumption practices. Hence, a crucial task for the further elaboration of MBIs in ESC is to connect inner and outer worlds as well as individual and social change agency. 


\section{Acknowledgements}

The authors would like to thank the entire project team and the project partners for their valuable feedback in the course of the development of the training as well as for their dedication and enthusiasm in supporting the intervention study. Another big thank you goes to the participants in the courses for their openness and insightful feedback. The present research has been made possible through funding received from the German Ministry for Education and Research (BMBF) in the project BiNKA (Education for Sustainable Consumption through Mindfulness Training) under grants 01UT1416 and 01UT1416B.

\section{References}

Adomßent, M., Fischer, D., Godemann, J., Herzig, C., Otte, I., Rieckmann, M., \& Timm, J.M. (2014). Emerging areas in research on higher education for sustainable development e management education, sustainable consumption and perspectives from Central and Eastern Europe. Journal of Cleaner Production, 62(1), 1-7.

Bahl, S., Milne, G. R., Ross, S. M., Mick, D. G., Grier, S. A., Chugani, S. K., \& Mariani, S. B. (2016). Mindfulness: The transformative potential for consumer, societal, and environmental well-being. Journal of Public Policy \& Marketing. https://doi.org/ 10.1509/jppm.15.139

Bandura, A., \& Schunk, D. H. (1981). Cultivating competence, self-efficacy, and intrinsic interest through proximal self-motivation. Journal of Personality and Social Psychology, 41, 586-598. doi: http://dx.doi.org/10.1037/0022-3514.41.3.586

Bodhi, B. (2011). What does mindfulness really mean? Contemporary Buddhism, 12. https://doi.org/10.1080/14639947.2011.564813

Boehme, T., Geiger, S., Grossman, P., Schrader, U., \& Stanszus, L. (2016). Arbeitsdefinition von Achtsamkeit im Projekt BiNKA. Working paper. Retrieved 12 January 2017, from http://achtsamkeit-und-konsum.de/?page_id=386\&lang=de

Bowen, S., Witkiewitz, K., Dillworth, T. M., Chawla, N., Simpson, T. L., Ostafin, B. D., \& Marlatt, G. A. (2006). Mindfulness meditation and substance use in an incarcerated population. Psychology of Addictive Behaviors, 20(3), 343-347. https://doi.org/ 10.1037/0893-164X.20.3.343

Broderick, P. C., \& Frank, J. L. (2014). Learning to BREATHE: An intervention to foster mindfulness in adolescence. New Directions for Youth Development, 142, 31-44. https://doi.org/10.1002/yd.20095

Burroughs, J. E., \& Rindfleisch, A. (2002). Materialism and wellbeing: A conflicting values perspective. Journal of Consumer Research, 29(3), 348-370. https://doi.org/ $10.1086 / 344429$

Carmody, J., \& Baer, R. A. (2008). Relationships between mindfulness practice and levels of mindfulness, medical and psychological symptoms and well-being in a mindfulness-based stress reduction program. Journal of Behavioural Medicine, 31(1), 23-33. https://doi.org/10.1007/s10865-007-9130-7

Chatzisarantis, N. L. D., \& Hagger, M. S. (2007). Mindfulness and the intentionbehaviour relationship within the theory of planned behaviour. Personality and Social Psychology Bulletin, 33(5), 663-676. https://doi.org/10.1177/014616720 6297401 
Chiesa, A. (2013). The difficulty of defining mindfulness: Current thought and critical issues. Mindfulness, 4(3), 255-268. https://doi.org/10.1007/s12671-012-0123-4

Condon, P., Desbordes, G., Miller, W.B., \& DeSteno, D. (2013). Meditation increases compassionate responses to suffering. Psychological Science, 24, 2125-2127.

Creswell, J. D. (2017). Mindfulness interventions. Annual Review of Psychology, 68, 491-516. https://doi.org/10.1146/annurev-psych-042716-051139

Groot, J.I.M., \& de Steg, L. (2008). Value orientations to explain beliefs related to environmental significant behaviour: How to measure egoistic, altruistic, and biospheric value orientations. Environment and Behaviour, 40, 330-354.

Ericson, T., Kjønstad, B. G., \& Barstad, A. (2014). Mindfulness and sustainability. Ecological Economics, 104, 73-79. https://doi.org/10.1016/j.ecolecon.2014.04.007

Fischer, D. (2016). Relevante konsumpädagogische Formate für die Entwicklung eines konsumspezifischen Achtsamkeitstrainings im Projekt BiNKA: Ergebnisse einer Sichtung und Bewertung. Retrieved 15 December 2016, from http://achtsamkeitund-konsum.de/wp-content/uploads/2015/09/Relevante_konsumpaedagogische_ Formate_fuer_BiNKA_2016_final.pdf

Fischer, D., \& Barth, M. (2014). Key competencies for and beyond sustainable consumption: An educational contribution to the debate. GAiA, 23(S1), 193-200. https://doi.org/10.14512/gaia.23.S1.7

Fischer, D., Stanszus, L., Geiger, S. M., Grossman, P., \& Schrader, U. (submitted). Mindfulness and sustainable consumption: A systematic literature review of research approaches and findings. Journal of Cleaner Production.

Grossman, P. (2010). Mindfulness for psychologists: Paying kind attention to the perceptible. Mindfulness, 1(2), 87-97. https://doi.org/10.1007/s12671-010-0012-7

Grossman, P. (2015). Mindfulness: Awareness informed by an embodied ethic. Mindfulness, 6(1), 17-22. https://doi.org/10.1007/s12671-014-0372-5

Grossman, P., Niemann, L., Schmidt, S., \& Walach, H. (2004). Mindfulness-based stress reduction and health benefits. Journal of Psychosomatic Research, 57(1), 35-43. https://doi.org/10.1016/S0022-3999(03)00573-7

Harfensteller, J. (2016). Relevante Achtsamkeitsformate für BiNKA - Bildung für Nachhaltigen Konsum durch Achtsamkeitstraining: Arbeitspapier. Retrieved 20 November 2016, from http://achtsamkeit-und-konsum.de/?page_id=386\&lang=de

Jarva, V. (2011). Consumer education for futures. International Journal of Home Economics, 4(2), 77-91.

Kabat-Zinn, J. (2011). Some reflections on the origins of MBSR, skilful means, and the trouble with maps. Contemporary Buddhism, 12(1), 281-306. https://doi.org/10. 1080/14639947.2011.564844

Kabat-Zinn, J. (1991, c1990). Full Catastrophe Living: Using the Wisdom of Your Body and Mind to Face Stress, Pain, and Illness. New York, N.Y: Pub. by Dell Pub., a division of Bantam Doubleday Dell Pub. Group.

Kaltwasser, V. (2008). Achtsamkeit in der Schule: Stille-Inseln im Unterricht: Entspannung und Konzentration. Weinheim und Basel: Beltz Verlag.

Kasser, T., Rosenblum, K. L., Sameroff, A. J., Deci, E. L., Niemiec, C. P., Ryan, R. M., \& Hawks, S. (2014). Changes in materialism, changes in psychological well-being: Evidence from three longitudinal studies and an intervention experiment. Motivation and Emotion, 38(1), 1-22. https://doi.org/10.1007/s11031-013-9371-4

Langer, E. J. (2000). The construct of mindfulness. Journal of Social Issues, 56(1), 1-9. 
Leiberg, S., Klimecki, O., \& Singer, T. (2011). Short-term compassion training increases prosocial behavior in a newly developed prosocial game. PloS one, 6(3), e17798. https://doi.org/10.1371/journal.pone.0017798

Lim, D., Condon, P., \& DeSteno, D. (2015). Mindfulness and compassion: an examination of mechanism and scalability. PloS one, 10(2), e0118221. https://doi.org/10. 1371/journal.pone.0118221

McGregor, S. L. T. (2005). Sustainable consumer empowerment through critical consumer education: a typology of consumer education approaches. International Journal of Consumer Studies, 29(5), 437-447. https://doi.org/10.1111/j.1470-6431.2005. 00467.x

Meiklejohn, J., Phillips, C., Freedman, M. L., Griffin, M. L., Biegel, G., Roach, A., \& Saltzman, A. (2012). Integrating mindfulness training into k-12 education: Fostering the resilience of teachers and students. Mindfulness, 3(4), 291-307. https://doi.org/ 10.1007/s12671-012-0094-5

Mindfulness All-Party Parliamentary Group (MAPPG). (2015). Mindful Nation UK. Retrieved 25 April 2017, from www.themindfulnessinitiative.org.uk.

Monteiro, L. M. (2016). Implicit ethics and mindfulness - Subtle assumptions that MBIS are value-neutral. International Journal of Psychotherapy (Extra Special e-Issue), 20, 210-224.

Monteiro, L. M., Musten, R. F., \& Compson, J. (2014). Traditional and contemporary mindfulness: Finding the middle path in the tangle of concerns. Mindfulness, 6(1), 1-13. https://doi.org/10.1007/s12671-014-0301-7

Nelson, K., \& Creagh, T. (2013). A Good Practice Guide: Safeguarding Student Learning Engagement. Sydney: University of Technology.

Petitmengin, C. (2006). Describing one's subjective experience in the second person: An interview method for the science of consciousness. Phenomenology and the Cognitive Sciences, 5(3-4), 229-269. https://doi.org/10.1007/s11097-006-9022-2

Pfattheicher, S., Sassenrath, C., \& Schindler, S. (2016). Feelings for the suffering of others and the environment. Compassion fosters proenvironmental tendencies. Environment and Behaviour, 48, 929-945.

Rechtschaffen, D. (2016). Die achtsame Schule: Achtsamkeit als Weg zu mehr Woblbefinden für Lehrer und Schüler: Arbor.

Richins, M. L., \& Dawson, S. (1992). A consumer values orientation for materialism and its measurement: Scale development and validation. Journal of Consumer Research, 19(3), 303. https://doi.org/10.1086/209304

Rieckmann, M., Mindt, L., \& Gardiner, S. (2017). Education for Sustainable Development Goals: Learning Objectives. Paris: UNESCO.

Rosenberg, E. L. (2004). Mindfulness and consumerism. In T. Kasser \& A. D. Kanner (Eds.), Psychology and consumer culture. The struggle for a good life in a materialistic world (1st Ed.). Washington, D.C: American Psychological Association.

Steg, L., Perlaviciute, G., van der Werff, E., \& Lurvink, J. (2014). The Significance of hedonic values for environmentally relevant attitudes, preferences, and actions. Environment and Behaviour, 46, 163-192.

Teasdale, J. D., Segal, Z. V., Williams, J. M. G., Ridgeway, V. A., Soulsby, J. M., \& Lau, M. A. (2000). Prevention of relapse/recurrence in major depression by mindfulness-based cognitive therapy. Journal of Consulting and Clinical Psychology, 68(4), 615-623. https://doi.org/10.1037/0022-006X.68.4.615 
United Nations (2015). Transforming Our World: The 2030 Agenda for Sustainable Development: Resolution adopted by the General Assembly on 25 September 2015. New York.

Wals, A. E. J. (2009). Review of Contexts and Structures for Education for Sustainable Development: Learning for a Sustainable World. Paris.

Correspondence concerning this paper should be addressed to MSc Laura Sophie Stanszus, Technische Universität Berlin, Marchstr. 23, 10587 Berlin, Germany. Email: Laura.stanszus@tu-berlin.de

\section{Appendix I.}

\section{Session 7 - "Mindful Consumption - To Have and to Be"}

The seventh session of the BiNKA-training connects formal mindfulness meditation with its practical dimension and incorporates the reflection of questions like "What has mindfulness to do with my consumption behaviour?" and "What does mindful consumption mean to me personally?" guided and facilitated by the trainer. Additionally and very importantly, the practice of loving kindness/metta meditation is deepened during the session and at home. The focus of the session is explicitly laid on the individual and the social/global dimension of mindful consumption. The cultivation of wholesome emotions (e.g., benevolence and compassion) instead of unwholesome emotions (e.g., greed and hatred) is shown as a way to establish an inner state of wellbeing and bliss, in contrast to the attempt to satisfy this need through excessive consumption and the accumulation of possessions. Moreover, light is shed onto the impact of one's consumption decisions (e.g., "Interdependence: A Pair of Jeans Travels around the World") and the participants are encouraged to practice benevolent and compassionate behaviour in everyday life.

Table 3

Procedure of Session 7

\begin{tabular}{lc}
\hline \multicolumn{1}{c}{ Element of session } & Min. \\
\hline Drop-in: Feeling the clothes on the skin & 3 \\
\hline Brief repetition of Session 6 and introduction of Session 7 & 2 \\
\hline $\begin{array}{l}\text { Guided meditation (metta stage 2): benevolence and compassion with oneself and } \\
\text { others }\end{array}$ & 20 \\
\hline Feedback/reflection of meditation practice and homework in group setting & 10 \\
\hline Mindful movement/relaxing the body & 5 \\
\hline $\begin{array}{l}\text { Informal exchange in dyads/triads: consumption behaviour in the context of } \\
\text { mindfulness }\end{array}$ & 10 \\
\hline Feedback/reflection in group setting & 5 \\
\hline $\begin{array}{l}\text { Consumption-specific mindfulness exercise "Interdependence: A Pair of Jeans Travels } \\
\text { around the World" }\end{array}$ & 15 \\
\hline $\begin{array}{l}\text { Feedback/reflection in group setting and interactive insight talk of teacher and } \\
\text { participants: Mindful consumption }\end{array}$ & 15 \\
\hline Setting an intention; reference to homework and course handouts & 5 \\
\hline
\end{tabular}

